\title{
Hantavirus pulmonary syndrome in Manitoba
}

\author{
L Robbin Lindsay $\mathrm{PhD}^{1}$, Michael A Drebot $\mathrm{PhD}^{1}$, Elise Weiss MD CCFP ${ }^{2}$, Harvey Artsob $\mathrm{PhD}^{1}$
}

LR Lindsay, MA Drebot, E Weiss, H Artsob. Hantavirus pulmonary syndrome in Manitoba. Can J Infect Dis $2001 ; 12(3): 169-173$.

\begin{abstract}
The first confirmed case of hantavirus pulmonary syndrome in Manitoba was diagnosed in 1999. To define better the risk of exposure to hantaviruses in this area, the clinical features and epidemiological factors pertaining to this case were described, and a serological survey of rodents collected near the patient's residence was undertaken. Small mammals were collected using live traps, were anesthetized via inhalation of isoflurane and were bled. Human and mouse serologies were undertaken using an ELISA to detect hantavirus-specific immunoglobulin $\mathrm{G}$ and/or immunoglobulin $\mathrm{M}$ antibodies. In addition, a full medical and epidemiological assessment, as well as individual risk factor and exposure analysis, were conducted. A 27-year-old Manitoba woman presented with severe respiratory distress and diffuse bilateral air space disease radiologically. Despite extremely aggressive measures, including mechanical ventilation, antibiotics, fluid management and inotropic support, the patient's condition rapidly deteriorated, and she died $8 \mathrm{~h}$ after admission. Hantavirus pulmonary syndrome was confirmed by the detection of immunoglobulin $\mathrm{M}$ and immunoglobulin $\mathrm{G}$ antibodies to the Sin Nombre virus (SNV) in her sera and by the demonstration of SNV genomic sequences in her lung tissue. Exposure to hantavirus likely occurred in and around the home or in the rural area in which she resided. A total of 252 small mammals, primarily deer mice (Peromyscus maniculatus), were collected from 17 different sites at or near where the patient lived. Antibodies to SNV were detected in 28 of 244 (11.5\%) deer mice, which were collected within $9 \mathrm{~km}$ of the residence of the fatal case, indicating that these rodents are a significant reservoir for SNV in this area.
\end{abstract}

Key Words: Deer mice; Hantavirus pulmonary syndrome; HPS; Peromyscus maniculatus; Rodents; Serosurvey; Sin Nombre virus

\section{Syndrome pulmonaire de l'hantavirus au Manitoba}

RÉSUMÉ : Le premier cas avéré de syndrome pulmonaire de l'hantavirus a été diagnostiqué pour la première fois au Manitoba en 1999. Afin de mieux circonscrire le risque d'exposition à l'hantavirus dans la région, nous fournissons une description du tableau clinique et des facteurs épidémiologiques propres au cas ainsi que les résultats des examens sérologiques effectués sur les rongeurs attrapés près de la résidence de la patiente. Les petits mammifères ont été capturés à l'aide de pièges permettant de les garder vivants, puis anesthésiés par inhalation d'isoflurane en vue d'une saignée. Nous avons ensuite effectué des examens sérologiques chez des personnes et des souris à l'aide du test ELISA pour déceler la présence d'immunoglobulines $G$ ou d'immunoglobulines M spécifiques de l'hantavirus. Nous avons également procédé à une évaluation médicale et épidémiologique complète ainsi qu'à une analyse des facteurs de risque de la patiente. Voici le cas d'une femme de 27 ans, du Manitoba, qui a consulté pour détresse respiratoire grave; elle présentait, à la radiologie, une atteinte diffuse et bilatérale des cavités aériennes. Malgré un traitement extrêmement énergique, composé de ventilation mécanique, d'antibiotiques, de fluides et de médicaments inotropes, l'état de la patiente s'est détérioré rapidement et elle est morte huit heures après son admission. Le diagnostic de syndrome pulmonaire de l'hantavirus a été confirmé par la présence d'immunoglobulines $G$ et d'immunoglobulines $M$ contre le virus Sin Nombre (VSN) dans le sérum et par la présence de séquences du génome du VSN dans les poumons. L'exposition à l'hantavirus a probablement eu lieu autour de la maison ou dans la région rurale environnante. Deux cent cinquante-deux petits mammifères, surtout des souris sylvestres (Peromyscus maniculactus), ont été capturés en 17 endroits près du lieu de résidence de la patiente. La présence d'anticorps a été décelée chez 28 des 244 souris sylvestres $(11,5 \%)$ vivant dans un rayon de $9 \mathrm{~km}$ autour de la maison. Un cas d'infection au VSN a été diagnostiqué au Manitoba. Les examens sérologiques effectués sur les animaux capturés près de la résidence de la patiente indiquent que les souris sylvestres constituent un réservoir important du VSN dans la région.

\footnotetext{
${ }^{1}$ Health Canada, National Microbiology Laboratory, Zoonotic Diseases and Special Pathogens, Canadian Science Centre for Human and Animal Health, Winnipeg, Manitoba; ${ }^{2}$ Manitoba Health, Marquette, Brandon and South Westman Regional Health Authorities, Brandon, Manitoba Correspondence and reprints: $\operatorname{Dr}$ L Robbin Lindsay, Room 4770, 1015 Arlington Street, Winnipeg, Manitoba R3E 3R3.

Telephone 204-789-6060, fax 204-789-2082, e-mail Robbin_Lindsay@hc-sc.gc.ca

Received for publication March 10, 2000. Accepted July 5, 2000
} 
$\mathrm{H}_{\mathrm{o}}^{\mathrm{a}}$ antavirus pulmonary syndrome (HPS) was initially recognized in the southwestern United States in 1993 (1). An outbreak of HPS was caused by a hantavirus originally called the 'Muerto Canyon' or 'Four Corners' virus (2), but which is now named the 'Sin Nombre' virus (SNV) (3). Since the original identification of the SNV, at least 12 other species of hantavirus have been identified in the Americas, including six that are known to be the etiological agent of HPS (3). Cases of HPS have been recognized in Canada but, to date, SNV is the only species of hantavirus that has been documented to cause HPS in this country.

Although the SNV has been shown to infect many rodent species, the deer mouse, Peromyscus maniculatus, is the primary reservoir of SNV in the southwestern United States (4). The deer mouse is widely distributed in Canada (5) and is believed to excrete SNV in urine, saliva and feces (6). Human infection usually occurs when aerosolized virus is inhaled $(3,6)$.

As of January 1, 2000, 32 Canadian cases of HPS had been confirmed in the laboratory. All cases were reported in British Columbia, Alberta, Saskatchewan or Manitoba, with a case fatality rate of $37.5 \%$, including the case described below (7). Patients ranged in age from 15 to 62 years (mean 39 years), and the majority (19 of 32 [60\%]) were male (7). Before 1999, human cases of HPS had not been recognized in Manitoba. However, in July 1999, a female died from HPS; she had recently relocated from McAuley, Manitoba to Brandon, Manitoba. To gain further information regarding this case, local public health authorities conducted a full medical and epidemiological assessment, as well as individual risk factor and exposure analysis. Personnel from the Zoonotic Diseases and Special Pathogens (ZDSP) program trapped and bled small mammals in and around the patient's principal residence and at 17 other sites within $9 \mathrm{~km}$ of this residence in southwest Manitoba.

The present paper describes the clinical presentation and laboratory findings for the first confirmed HPS case in Manitoba, as well as the distribution and prevalence of hantavirus infections in the small mammals collected at 17 sites in southwestern Manitoba.

\section{SUBJECTS AND METHODS}

Epidemiological investigation: Following laboratory confirmation of the first case of HPS in Manitoba, local public health authorities conducted a full medical and epidemiological assessment, as well as individual risk factor and exposure analysis.

Sampling of small mammals: During the field investigation for the present HPS case, the trapping effort focused on the rural property located southwest of McAuley, Manitoba where the patient had lived and on 17 other sites within $9 \mathrm{~km}$ of this location. The entire area where sampling was conducted was approximately $16 \times 10 \mathrm{~km}$, the median distance from the patient's residence to other trapping sites was $3.2 \mathrm{~km}$, and the average distance among these sites was $4.3 \mathrm{~km}$ (range 0.8 to $9 \mathrm{~km}$ ).
Small mammals were collected in Sherman live traps (HB Sherman Traps Inc, USA) set each evening from July 17 to 22,1999 . All traps were baited with a mixture of peanut butter and rolled oats; they were set in the late afternoon and checked the following morning. The majority of the traps were set within buildings such as the home of the patient, storage sheds, barns, granaries, or abandoned or infrequently used vehicles. At most other locations, traps were set in or at the edge of wooded or grassland habitats. Animals were anesthetized by the inhalation of isoflurane such as Aerrane (Anaquest, USA). They were bled via the retro-orbital sinus using Natelson (Fisher Scientific, USA) blood collecting tubes or by cardiac puncture. Sera from these blood samples were obtained by centrifugation at $15,000 \mathrm{rpm}$ for 5 to $10 \mathrm{~min}$ in Microtainer (Becton Dickinson, USA) serum separators.

Serological testing: Human and rodent serum samples were tested for antibodies to SNV using an ELISA. Sera from rodents were only tested for immunoglobulin (Ig) G antibodies whereas human sera were tested for both IgM and IgG antibodies. The ELISA for IgG antibodies in rodents was an indirect test in which plates were coated with recombinant SNV N-protein (ie, positive antigen - lot \#SPR 293, Centers for Disease Control and Prevention [CDC], USA) and recombinant nonviral protein mixture (ie, negative antigens - lot \#SPR 292, CDC). Test sera were diluted 1:100 with master plate diluent for the initial screening, and the peroxidase conjugates were comprised of equal volumes of goat anti-rat (lot \#UB050, CDC) and goat anti-Peromyscus (lot \#SB30, $\mathrm{CDC}$ ). Positive controls consisted of sera from deer mice known to be infected (lot \#703110, CDC), whereas negative controls were sera from a colony of deer mice at the University of Manitoba (Winnipeg, Manitoba) that had previously tested negative to the SNV. The ELISA for IgG antibodies in human sera was identical to that used to test rodent sera for IgG antibodies, except that the conjugate was goat anti-human IgG (catalogue \#074-1006, Kirkegaard \& Perry Laboratories, USA), positive controls consisted of positive human sera (lot \#703109, CDC), and negative controls consisted of human sera that had previously tested negative for SNV (HAN-389/95, ZDSP).

For the ELISA test for IgM antibodies in human sera, plates were coated with goat anti-human IgM (catalogue \#AHI 0601, Biosource International, USA). Test sera were diluted 1:100 for the initial screening and added to positive control wells (ie, inactivated cell culture propagated SNV lot \#SPR 305, CDC) and negative wells (ie, cell slurry of E6 Vero cells - lot \#SPR 306, CDC). Hyperimmune mouse antiSNV antibody (lot \#703110, CDC) was added at 1:1000 followed by peroxidase conjugated goat anti-mouse IgG (catalogue \#074-1806, Kirkegaard \& Perry Laboratories). Control sera were human sera that had previously tested positive (HAN 262/98, CDC) or negative (lot \#MA 757/88, ZDSP). All sera that reacted at the screening dilution of $1: 100$ were titrated by fourfold dilution in serum diluent to a maximum end point of 1:6400, and samples with antibody titres 1:400 or greater were considered positive. 


\section{CASE PRESENTATION}

A 27-year-old female patient was admitted to the Brandon Regional Health Centre on July 5, 1999. Six days before admission, she developed fever, headache, vomiting, weakness and lethargy. On July 4, 1999, she entered the emergency department, where she was treated for presumed gastroenteritis and discharged. The next day, she was admitted to the same hospital after presenting with dry cough and worsening respiratory symptoms. She was pale, cool to the touch, hypoxic and hypotensive, with a blood pressure of $74 / 48 \mathrm{mmHg}$, a pulse rate of 130 beats/min, a respiratory rate of 30 to 40 breaths $/ \mathrm{min}$ and a temperature of $35.8^{\circ} \mathrm{C}$. She had bibasilar crepitations and an initial oxygen saturation of $74 \%$ on room air. Laboratory findings were: hemoglobin $190 \mathrm{~g} / \mathrm{L}$, hematocrit 0.572 , leukocyte count $12.2 \times 10^{9} / \mathrm{L}$ with $86.3 \%$ mature polymorphs, platelet count $38 \times 10^{9} / \mathrm{L}$, serum sodium level $133 \mathrm{mmol} / \mathrm{L}$, urea level $4.8 \mathrm{mmol} / \mathrm{L}$ and creatinine level $0.09 \mathrm{~mol} / \mathrm{L}$. Chest X-ray showed prominent bilateral air space disease. A provisional diagnosis of noncardiogenic adult respiratory distress syndrome was made, and she was treated empirically with cefuroxime, clindamycin and erythromycin. She was immediately transferred to the intensive care unit, where she had rapidly progressive respiratory deterioration requiring intubation and mechanical ventilation. She became hemodynamically unstable, requiring inotropic support, and she arrested twice before succumbing $8 \mathrm{~h}$ after admission.

Postmortem examination was consistent with noncardiogenic adult respiratory distress syndrome secondary to viral etiology, possibly hantavirus. Bacterial cultures from endotracheal secretions, blood cultures and urine were negative. The diagnosis of HPS was subsequently confirmed by the detection of IgM (titre $1: 1600$ ) and IgG (titre 1:400) antibodies to the SNV in the patient's sera. Reverse transcription polymerase chain reactions using hantavirus-specific primers (8) also detected the presence of the viral genome within the patient's lung biopsy tissue. Serological tests conducted on samples collected from family members and household contacts in mid to late July were negative, with the exception of a 13-year-old male who had significant IgG antibody titres (1:400) for the SNV, but who was IgM-negative and asymptomatic.

\section{RESULTS}

Rodent sampling and serosurvey for the SNV: At sites near McAuley, Manitoba, a total of 252 animals from three mammalian species were captured. The deer mouse, Peromyscus maniculatus, was the predominant species, accounting for more than $96 \%$ of the total number of captures. A total of 244 deer mice were collected from 17 of 18 sites where traps were set, including 33 animals collected on the property where the patient had lived. Deer mice with antibodies against SNV were identified at seven of these 17 localities. Although none of the 33 deer mice collected on the patient's former residence had evidence of infection, deer mice with antibody titres were found at sites within $1 \mathrm{~km}$ of this site. The capture sites of seropositive deer mice were randomly distributed within the entire study area, with no obvious clustering of sites harbouring infected animals. At the sites where animals with antibody titres were identified, the proportion of animals with SNV antibodies ranged from $12.5 \%$ to $33.3 \%$. Sera from six red-backed voles, Clethrionomys gapperi, and two brown rats, Rattus norvegicus, did not have recognizable antibody titres to hantavirus. Overall, 28 of the 244 deer mice $(11.5 \%)$ from sites near McAuley had antibody titres against the SNV.

\section{DISCUSSION}

Since 1994, personnel from the ZDSP program have been conducting serological surveillance for hantavirus antibodies in deer mouse populations across Canada (7). Seropositive deer mice have been collected in the Yukon Territory, British Columbia, Alberta, Saskatchewan, Manitoba, Ontario, Quebec, New Brunswick and Newfoundland (unpublished data, ZDSP). However, confirmed cases of HPS have now only been reported in the four westernmost provinces in Canada. This is the first report of the seroprevalence of hantaviruses in deer mice collected in Manitoba. The hantavirus from deer mice collected in southwestern Manitoba has been shown, by genetic analysis (8), to belong to a western genogroup of SNV-like viruses (unpublished data, ZDSP). Thus, although hantaviruses are widely distributed within deer mouse populations in Canada, only SNV-like hantaviruses found in western Canada are associated with cases of HPS to date.

Hantaviruses are known to infect rodents, in which they produce asymptomatic chronic infection with viral shedding in urine, feces and saliva. Rodent to human transmission occurs primarily by the inhalation of infected rodent excretions, particularly freshly shed urine (6). It is possible that infectious airborne particles may be generated during human activities that disturb contaminated soil, litter or nesting materials. Small skin breaks and rodent bites are probably effective but uncommon routes of human infection. Ticks, fleas, mosquitoes and other biting arthropods are not known to have a role in the transmission of hantaviruses. Although cats and dogs are not known to be a reservoir of hantaviruses, these domestic animals may bring infected rodents into contact with humans (3). The risk of human disease is proportional to the frequency with which people come into contact with infectious rodents or their excreta, the relative abundance of deer mouse populations, and the prevalence of hantavirus infection in these rodents $(3,9)$.

The Manitoba case occurred in an area of southwestern Manitoba where the deer mouse is the predominant species and where the prevalence of infection among the sampled mice was $11.5 \%$. Although not directly involved in farming operations, the infected woman lived in a rural setting where deer mice are typically abundant, and hence, there was a relatively high probability of contact with deer mice and/or their excreta. Furthermore, mouse droppings were found in the trunk of the car that she commonly drove. In addition, a family cat frequently brought home deer mice, which the patient 
handled. Thus, exposure to hantavirus likely occurred in and around the home or in the rural area in which she resided. In fact, $70 \%$ of the HPS cases in Canada most likely were exposed to the SNV during farming and domestic activities in rural areas (10). Single cases have also been linked to occupational exposure during military exercises, lumber mill cleanup and wildlife surveying $(7,10)$. The prevalence of antibodies against the SNV in deer mice ranged from $12 \%$ to $33 \%$ at sites where at least one positive mouse was collected. This percentage of seropositive deer mice was comparable with that observed in areas of Alberta where HPS is more frequently observed (unpublished data, ZDSP).

The clinical presentation of the present case conforms to the usual pattern (11). Cardiopulmonary dysfunction, ranging from mild hypoxemia with stable hemodynamics to rapidly progressive respiratory failure with cardiogenic shock, is the hallmark of patients with fully developed HPS. Patients generally present with an initial period of fever (often with chills) and myalgia, and many have gastrointestinal complaints such as nausea or vomiting, abdominal pain or diarrhea. Some patients, such as the present case, have been sent home from the emergency room with these nonspecific symptoms, only to return several hours or a few days later, extremely ill. Dyspnea typically develops just before hospitalization, concurrent with respiratory decompensation and the advent of pulmonary edema. The average duration of illness before hospitalization is three to four days, and, in those patients who deteriorate, the usual duration of illness is an additional one to three days until death. However, patients can die within hours of admission. Some patients complain of cough but, if present, it develops late in the prodrome. On initial evaluation, a triad of thrombocytopenia, increased immature granulocytes (often with an elevated white blood cell count) and large immunoblastoid lymphocytes is characteristic. Hemoconcentration may be remarkable, and prolongation of the partial thromboplastin time and the prothrombin time is often seen. Elevated serum lactate levels have been observed in a majority of patients (11).

The most effective way to decrease the risk of developing HPS is to limit people's exposure to rodents and their excreta. Measures to prevent HPS can be divided into four areas: eliminating rodent harbourage, controlling deer mouse populations, properly cleaning areas contaminated by deer mouse excreta and avoiding these rodents in outdoor settings $(3,9)$. The importance of identifying personal risk and adhering to risk reduction measures should be emphasized through health education programs. Because early recognition of a case may improve the patient's chance of survival, physicians and other medical personnel play an important role in early case identification. Therefore, educational programs should be targeted to all medical personnel and should focus on the clinical features of the disease, diagnosis, patient management and treatment, and prevention recommendations. Other health professionals, such as public health officials, epidemiologists and public health educators, need to be knowledgeable about maintaining an active surveillance sys- tem and developing effective community-based educational programs. Clearly, pertinent information on the prevention of this disease should be available to the general public in Manitoba; however, a concerted effort should be made to inform those at greatest risk of exposure (ie, people living and working in rural environments both on a full-time [producers] and part-time [cottage owners] basis). Education and simple preventive measures are the best approaches toward minimizing exposure to and infection with hantavirus.

\section{ADDENDUM}

Since writing this manuscript, a second case of HPS was confirmed in southwestern Manitoba. The patient was a 68-year-old female who lived in a rural town within $100 \mathrm{~km}$ of McAuley. The onset of symptoms occurred in the middle of May 2000, and she was hospitalized after a five-day history of cough, nausea and vomiting. Due to rapidly progressive respiratory deterioration, she was transferred to a regional intensive care centre where she required intubation and mechanical ventilation. She died $4 \mathrm{~h}$ after admission, and HPS was confirmed when IgM and IgG antibodies to the SNV (both 1:400) were detected in her sera. Exposure to the SNV likely occurred in and around her home during gardeningrelated activities. A field investigation was conducted from June 19 to 20, 2000; traps were set at 16 locations distributed within a $100 \mathrm{~km}^{2}$ area around the rural town where she had lived. The results of the investigation were similar to those reported in the current paper. Deer mice with antibodies were collected at six of the $13(46.1 \%)$ locations sampled, and 10 of the $67(14.9 \%)$ deer mice were seropositive. The prevalence of antibodies within each locality ranged from $18.2 \%$ to $40 \%$.

ACKNOWLEDGEMENTS: The authors thank Kimberley Holloway, Antonia Dibernardo, Zhaoxia Chen and Maya Andonov of the ZDSP program for undertaking the laboratory diagnostics and providing logistical support for the field studies. The authors are also grateful to the residents of the McAuley area, who kindly provided access to their properties so that rodents could be collected. A special debt is owed to Charlie and Greg Coleman, who helped to organize the field collections at the McAuley sites and provided invaluable assistance during small mammal sampling.

\section{REFERENCES}

1. Outbreak of acute illness - Southwestern United States, 1993. MMWR Morb Mortal Wkly Rep 1993;42:421-4.

2. Update: Outbreak of hantavirus infection - Southwestern United States, 1993. MMWR Morb Mortal Wkly Rep 1993;42:477-9.

3. Hantavirus in the Americas. Guidelines for diagnosis, treatment, prevention and control. Technical Report Paper \#47. Washington: Pan American Health Organization, 1999:1-63.

4. Childs JE, Ksiazek TG, Spiropoulou CF, et al. Serologic and genetic identification of Peromyscus maniculatus as the primary rodent reservoir for a new hantavirus in the southwestern United States. J Infect Dis 1994;169:1271-80.

5. Banfield AWF. Mammals of Canada. Toronto: University of Toronto Press, 1974:164-70.

6. Wells RM, Peters CJ, Nichol ST, et al. Hantavirus transmission in the United States. Emerg Infect Dis 1997;3:361-5.

7. Drebot MD, Werker D, Artsob H. Hantavirus pulmonary 
syndrome in Canada: 1989-1999. Can Commun Dis Rep 2000;26:65-9.

8. Drebot MD, Tipples GA. Application of molecular diagnostics for the surveillance of hantavirus and measles virus in Canada. Can J Infect Dis 1998;9:71-5.

9. Hantavirus infection - Southwestern United States: Interim recommendations for risk reduction, 1993.
MMWR Morb Mortal Wkly Rep 1993;42:1-13.

10. Werker D, Artsob H. Of mice and mostly men hantavirus pulmonary syndrome. CMAJ 1998; $158: 123-5$.

11. Peters CJ, Simpson GL, Levy H. Spectrum of hantavirus infection: hemorrhagic fever with renal syndrome and hantavirus pulmonary syndrome. Ann Rev Med 1999;50:531-45. 


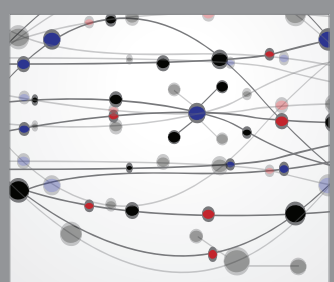

The Scientific World Journal
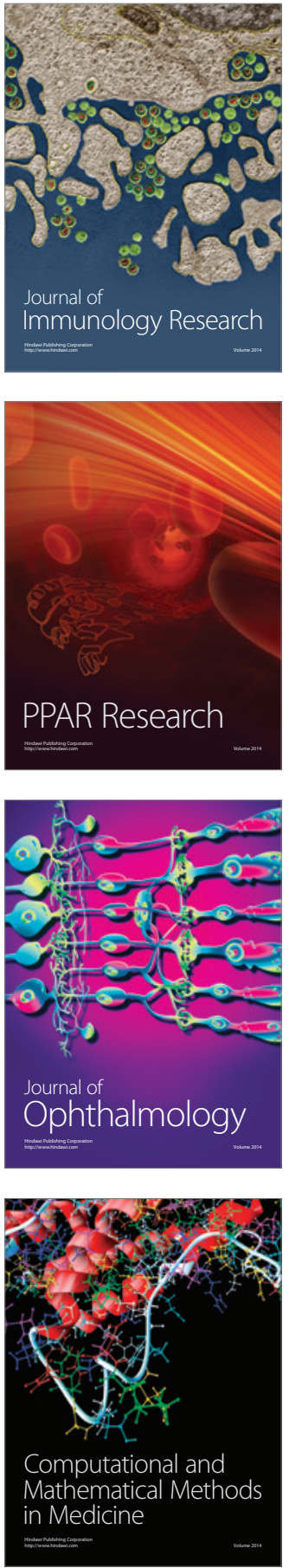

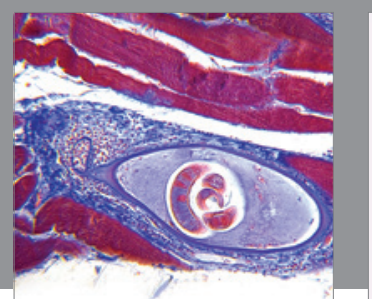

Gastroenterology Research and Practice

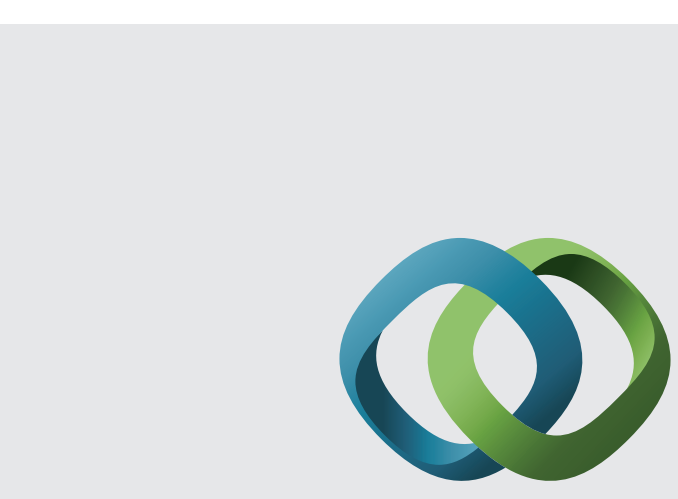

\section{Hindawi}

Submit your manuscripts at

http://www.hindawi.com
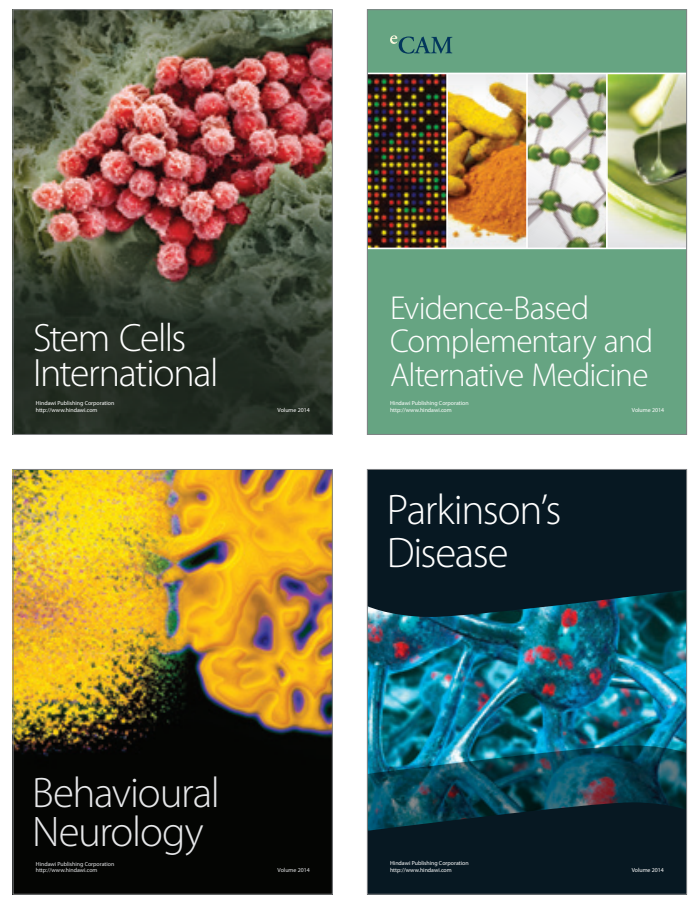
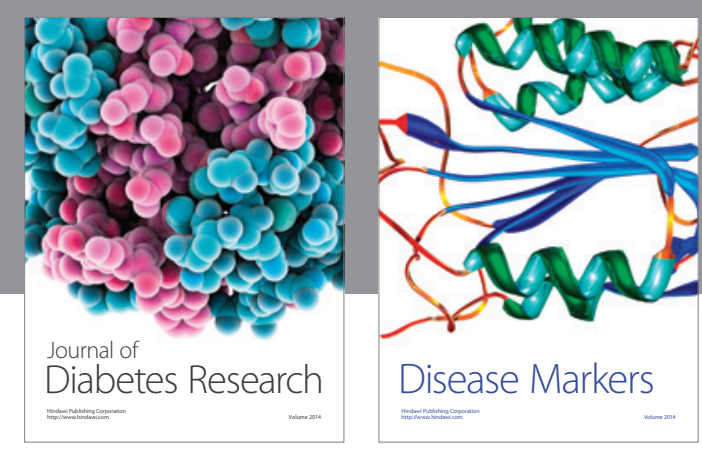

Disease Markers
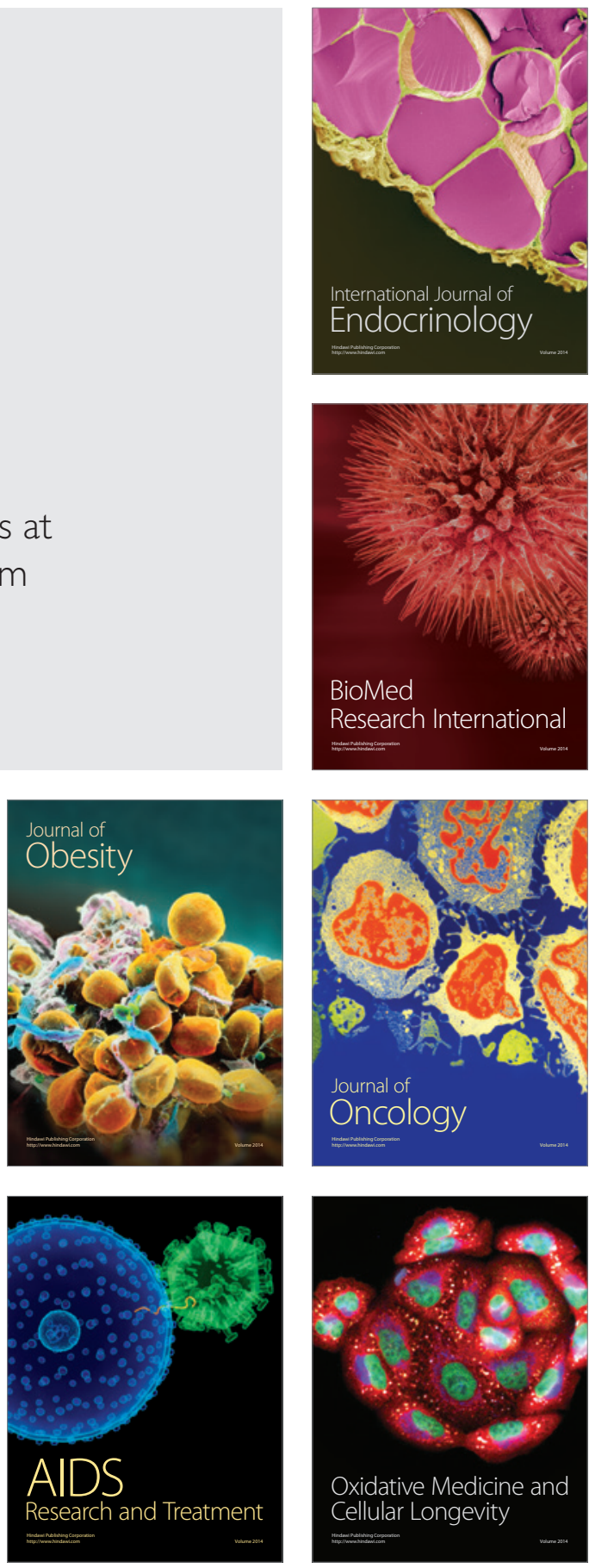